\title{
Machado com Flaubert e a Escrita Anti-Bêtise
}

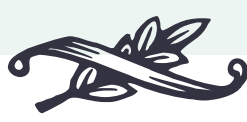

Lívia Cristina Gomes

RESUMO: Estuda-se aqui os textos "O imortal”, de Machado de Assis, e "La légende de Saint Julien l'Hospitalier", de Gustave Flaubert, considerando o jogo irônico de suas escritas, que faz do repertório de clichês a estratégia narrativa comum a ambos os autores.

PALAVRAS-CHAVE: Machado de Assis, Gustave Flaubert, ironia, lugar comum.
ABSTRACT: The texts "O imortal", by Machado de Assis, and "La légende de Saint Julien l'Hospitalier", by Gustave Flaubert, are studied here taking into consideration the ironic play of their writings which make the list of clichés cliché's list a narrative strategy common to both authors.

KEYWORDS: Machado de Assis, Gustave Flaubert, irony, cliché.

"Os 'dentes da calúnia' e outras expressões, surradas como colchões de hospedaria, são os seus encantos". Essa passagem do conto machadiano "Galeria póstuma", publicado em Histórias sem data em 1884, bem poderia apontar, não sem ironia, o próprio procedimento de escrita de Machado. A recorrência de imagens clichês é notável nos textos desse autor que, "a despeito de todo idealismo, projeta um leitor francamente anti-romântico, ou pelo menos disposto a romper com as convenções das narrativas tradicionais" (GUIMARÃES, 2004, p. 138). De modo semelhante, Gustave Flaubert, outro escritor oitocentista, faz da hipertrofia da frase o esvaziamento semântico do texto. Em outras palavras, é pela repetição e pelo acúmulo de lugares comuns que as escritas desses dois autores evidenciam a besteira da repetição do Mesmo, da repetição acrítica do já-dito.

O artigo que se segue propõe, portanto, uma aproximação entre Machado e Flaubert que não concerne às questões tradicionais da Literatura Comparada. Não se trata de abordar citações implícitas ou explícitas, "fonte" ou "influência" literária, mas sim do jogo irônico de suas escritas, que faz do repertório de clichês a estratégia narrativa comum a ambos os autores. Pois, encenando o desgaste substancial da palavra, as escritas de Machado e de Flaubert (des)fazem-se em simulacros que ficcionalizam o próprio procedimento narrativo. Nelas, as semelhanças discursivas que aristotelicamente fundamentariam a representação mimética ${ }^{2}$ se dissolvem na ironia que aponta o clichê e a tópica enunciada, sublinhando o vácuo discursivo de que são feitas. Isto é, suas escritas jogam com a inadequação daquilo que, pela semelhança entre discursos, ativaria a causalidade da verossimilhança, deslocando o texto do que o leitor considera "verdadeiro", seja como "verdade" ou "realidade" do equívoco positivista que substancializa os discursos pelos critérios validados da experiência empírica, seja como o verossímil segundo a lógica do gênero textual.

Frustrando as expectativas de leitura pelo redirecionamento das narrativas, a evidência dos próprios artifícios inscreve os textos no jogo do pastiche, ressonância do já-dito que indica a artificialidade da tópica. Não por acaso, o emprego sistemático da ironia nessas escritas é figurado pela comparação, figura de linguagem que enfatiza as semelhanças ${ }^{3}$. Espécie de curto-circuito da verossimilhança literária, a imagem clichê da comparação faz a escrita se voltar para si mesma, num movimento irônico

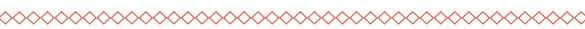

${ }^{1}$ Mestre em Letras pelo Programa de Pós-Graduação em Estudos Linguísticos, Literários e Tradutológicos em Francês da Universidade de São Paulo (USP). É integrante do GELLE (Grupo de Estudos Literatura Loucura Escritura). E-mail: livia.gomes@usp.br

${ }^{2}$ Sabe-se que, conforme Aristóteles (1370a, 1991), o verossímil se fundamenta pela semelhança do discurso com as opiniões que o avaliam como "verdadeiro", segundo seu gênero textual.

${ }^{3}$ Entenda-se que o importante aqui não é a figura de linguagem, "comparação" ou "metáfora”, segundo a definição de determinada preceptiva poética, mas a ironia da escrita que se condensa na construção da imagem literária. Com isso, justifica-se neste artigo o emprego um tanto indiscriminado entre os termos "comparação", "metáfora" e "figura". 
de pontuação da tópica narrada com o lugar-comum da construção imagética. Veja-se os seguintes excertos de "La légende de Saint Julien l'Hospitalier", conto flaubertiano integrante do volume Trois contes, publicado em 1877, e, em seguida, de "O imortal", de Machado de Assis, publicado na revista A Estação, entre 15 de julho e 15 de setembro de 1882:

Il combattit des Scandinaves recouverts d'écailles de poisson, des Nègres munis de rondaches en cuir d'hippopotame et montés sur des ânes rouges, des Indiens couleur d'or et brandissant par-dessus leurs diadèmes de larges sabres, plus clairs que de miroirs ${ }^{4}$. (FLAUBERT, [1877] 1973, p. 104-105)

Após a praga de parricídio proferida por um cervo negro num dia de caça de grande carnificina, Julien, acreditando ter matado sua mãe por tê-la confundido com uma cegonha, foge do castelo de seus pais. Sem destino, engaja-se numa tropa de aventureiros e percorre várias peripécias, como as descritas no trecho acima. Nota-se que o excesso de aventuras é acentuado pelo ritmo acelerado do texto: vários lances, separados apenas por vírgulas, hipertrofiam a frase e culminam na comparação, tão clichê quanto as aventuras narradas. Sem deixar o leitor tomar fôlego, uma nova série de aventuras vem logo em seguida:

Il vainquit les Troglodytes et les Anthropophages. Il traversa des régions si torrides que sous l'ardeur du soleil les chevelures s'allumaient d'elles-mêmes, comme des flambeaux; et d'autres qui étaient si glaciales que les bras, se détachant du corps, tombaient par terre; et des pays où il y avait tant de brouillard que l'on marchait environné de fantômes ${ }^{5}$ 2004, p. 71).]. (FLAUBERT, [1877] 1973, p. 105)

O mecanismo é o mesmo. A hipertrofia da frase, se por um lado é aliviada pelo ponto final, isto é, pela pausa um pouco mais duradoura entre a enumeração de aventuras, por outro, aumenta o exagero delas. Basta lembrar o que significa lutar contra (e ainda vencer) trogloditas e antropófagos. E mais uma vez o imaginário kitsch dessas superaventuras desemboca na comparação, igualmente lugar-comum. Também clichê é a maldição do cervo que se realiza: pensando vingar a suposta traição de sua mulher, Julien assassina o casal que dormia em sua cama: eram seus pais que, em sua ausência, tinham chegado ao castelo do filho. Da tópica da fatalidade ao velho clichê amor-traição-vingança, Julien foge novamente, "mendiant sa vie par le monde", até socorrer um leproso, a quem oferece seus mantimentos e seu calor. Abraçado com o doente, "Julien monta vers les espaces bleus, face à face avec Notre-Seigneur Jésus, qui l'emportait dans le ciel” (p. 128-129). De tópica em tópica, a comparação assinala a própria construção artificiosa e produz o tom irônico do pastiche, pois, repetindo o mesmo procedimento de escrita ao longo da narrativa, sublinha o convencionalismo das fórmulas enunciadas. Quanto a “O imortal”, os clichês não são diferentes:

Rui de Leão inculcava ser o próprio pai do Duque de Monmouth, suposto filho natural de Carlos II, e caudilho principal dos rebeldes. A verdade é que eram parecidos como duas gotas d'água. Outra verdade é que lady Ema [amante de Rui], por ocasião da guerra civil, tinha o plano secreto de fazer matar o duque, se ele triunfasse, e substituí-lo pelo amante, que assim subiria ao trono de Inglaterra. (ASSIS, [1882] 2006, v. 2, p. 892)

A narração das aventuras incríveis de Rui de Leão, cujo nome ecoa como pastiche do monarca Ricardo Coração de Leão, lembra o atropelamento da série de façanhas de Julien. De fato, tem-se

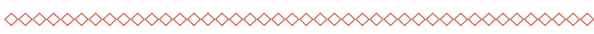

\footnotetext{
${ }^{4}$ Segue-se a tradução brasileira de Milton Hatoum e Samuel Titan Jr.: "Combateu os escandinavos recobertos de escamas de peixes, os negros munidos de broquéis de couro de hipopótamo e, montados sobre asnos vermelhos, os indianos de pele dourada, brandindo por cima dos diademas seus longos sabres, mais claros que espelhos.” (FLAUBERT, [1877] 2004, p. 71).

5 “Venceu os Trogloditas e os Antropófagos. Atravessou terras tão quentes que, sob o sol ardente, os cabelos pegavam fogo por si sós, como tochas; e ainda outras, tão glaciais que os braços, destacando-se do corpo, caíam por terra; e países onde havia tanto nevoeiro que se caminhava cercado de fantasmas". (FLAUBERT, [1877]).
} 
o mesmo procedimento: as aventuras excessivas e extraordinárias, que contam ainda com o "plano secreto" da amante, são narradas umas atrás das outras, com algumas comparações que apontam o pastiche do lugar-comum, sendo elas também comuns. Nada mais sem originalidade do que "parecidos como duas gotas d'água": eis a vulgaridade da comparação que, como em Flaubert, aponta o kitsch das tópicas narradas, evidenciando, ironicamente, as semelhanças desfeitas que fundamentavam a "verdade" (isto é, o "verdadeiro" ou verossímil) da peripécia.

Não teve outro recurso mais do que fugir; veio para o Sul, onde alguns anos depois, no princípio do século passado, podemos achá-lo na descoberta das minas. Era um modo de afogar o desespero, que era grande; pois amara muito a mulher, como um louco... (ASSIS, [1882] 2006, v. 2, p. 896)

Da Inglaterra, poucas páginas depois, o pernambucano Rui de Leão encontra-se de volta ao Brasil, após nova série de aventuras em diversos lugares em que viveu. O lugar-comum romântico não poderia ser melhor: amar "como um louco" bem merece as reticências no final. O tom aparentemente sério do "podemos achá-lo" logo se desfaz. A comparação, mais kitsch impossível, destrói qualquer seriedade que poderia haver no conto: sua própria mediocridade é indicadora do pastiche irônico da aventura amorosa. A história de Rui de Leão, contada por seu filho a dois amigos numa noite "escura como breu, quente como forno", se resume em uma sucessão de lances romanescos, repetindo sempre os mesmos tópicos: amor-ciúme-traição-vingança, até que, cansado das mesmas aventuras, “abatido e desencantado" (p. 899-900), Rui de Leão resolve tomar o restante do elixir que lhe dera a imortalidade. De clichês à tópica homeopática: o imortal finalmente morre.

Cabe ainda ressaltar que em "La légende de Saint Julien l'Hospitalier" o pastiche começa pelo título: o gênero legendário por ele indicado se justapõe ao gênero "conto", do título do livro, Trois contes. Descartada a função de guia de leitura - o que para leitores brasileiros ressoa como uma das velhas manobras machadianas -, o título ainda traz outro pastiche: o da Legenda áurea, conjunto de narrativas medievais que, entre outras histórias, conta a santificação de Julien, lida por Flaubert. A fórmula que abre o conto também não escapa: começando como uma narrativa exemplar semelhante à abertura de "Era uma vez...", o pastiche prossegue sublinhado pela comparação. A figura que parece mimetizar a tópica medieval explicitada no final do conto - a saber, a encenação de um narrador que se apresenta em primeira pessoa, mas que adquire o papel de toda uma comunidade representada pelo pronome on ${ }^{6}$, justificando, assim, a verossimilhança do lugar-comum da imagem - acaba por deslocar a possibilidade de uma simples repetição da tópica pela ironia do pastiche. O que a comparação põe em jogo não é a adequação verossímil a uma tópica medieval, mas, ao contrário, a inverossimilhança da narrativa, dada pela inverossimilhança de sua representação para o público do século XIX, visto que os valores éticos e morais representados pelo conto já se tornaram antiquados, não funcionando mais, portanto, como critérios de legibilidade normativa da literatura - embora o kitsch continue agradando ao "bom povo", nos dizeres de Machado, nas telenovelas.

Talvez convenha repetir que, de acordo com a retórica aristotélica, a representação não é simples reflexo do mundo empírico, mas se fundamenta numa construção discursiva verossímil desse mundo, cuja verossimilhança é variável de acordo com o gênero literário, isto é, de acordo com a opinião daquilo que é considerado discursivamente "verdadeiro" para determinado gênero. O "verdadeiro" de um texto, dado pela semelhança do discurso com as opiniões que assim o consideram, é, portanto, sua lógica discursiva, a coerência que o faz ser verossímil. Voltando então a Flaubert, a escrita desativa a representação mimética do conto, uma vez que a ironia do pastiche a desloca constantemente, ressaltando sua inadequação à seriedade do gênero legendário. Ou, em outros termos, propõe outro

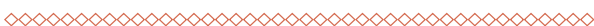

6 "Et voilà l'histoire de saint Julien l'Hospitalier, telle à peu près qu'on la trouve, sur un vitrail d'église, dans mon pays". Segundo a nota fornecida pela edição organizada por Samuel S. de Sacy do texto de Flaubert, "esse emprego da primeira pessoa, aparentemente tão contrário a sua doutrina [a de Flaubert e a seu costume, é na verdade um artifício de retórica; para ele, trata-se de imitar o tom oral dos antigos narradores" (FLAUBERT, [1877] 1973, p. 129; tradução minha) 
tipo de verossimilhança que não se pauta mais pela semelhança mimética, já que, pensando com Julia Kristeva ([1969] 1974, p.132), "falar nos restringe ao verossímil".

Proposta também feita por Machado: reescrevendo outro conto publicado em 1872 - "Ruy de Leão", segundo Jean-Michel Massa (1971, p. 534) -, a escrita de "O imortal" desloca a verossimilhança da tópica amorosa da narrativa anterior, tornando-a inverossímil como no caso flaubertiano, visto que, dez anos depois, as aventuras de Rui são consideradas, no mínimo, démodées e sua tópica, ultrapassada. Isto é, o idealismo romântico dos anos de 1870, que caracterizava o cenário literário brasileiro com José de Alencar e Visconde de Taunay, entre outros, já se mostra antiquado no início da década seguinte com as estéticas realista e naturalista, estreadas pelo romance $O$ mulato (1881), de Aluísio Azevedo. Porque os valores idealistas do romantismo se tornam kitsch no final do século XIX com a desfaçatez das ideologias que os sustentavam. Como nota Hermann Broch (2001, p. 28), "o kitsch só pôde nascer do romantismo e precisamente do romantismo", na derrocada da imbricação da figura autoral com a "expressividade" e a "originalidade" românticas, do momento em que surge o homem como sujeito autêntico e pleno. Desse eu absoluto, o kitsch é sua hipocrisia na luta de classes marxista ou no inconsciente da teoria psicanalítica. Ou ainda, de acordo com Hansen,

Como um avô de Pierre Ménard, no entanto, em 1882 o mesmo conto já não era o mesmo de 1872: Memórias póstumas de Brás Cubas evidencia que era já impossível ler como discurso sério o romanesco romântico com que recheia os lugares-comuns da vida fantástica de Rui de Leão. O romantismo continuaria a divertir o "bom povo", como agora, com o kitsch da ideologia do ideal, complicação sentimental, aventuras e intrigas; em 1882, contudo, a mesma história que diverte também perverte a diversão, pois subordina os lugares-comuns e os efeitos fantásticos a outros fins. (HANSEN, 2006, p. 61)

Isto posto, a vulgaridade da figura, que, num primeiro momento, parece compatível com a situação inicial encenada na narrativa, isto é, a narração do filho de Rui a seus dois amigos, logo deixa entrever que não é só isso: o diálogo, ao pôr em cena o destinatário do conto, distancia criticamente seu leitor pela inverossimilhança da tópica já tornada piegas.

Dito de outro modo, "La légende de Saint Julien l'Hospitalier" e "O imortal" estruturam-se pelo acúmulo: a demasia de episódios kitsch é reiterada pela repetição da imagem, como se apenas as aventuras do santo e do fidalgo não bastassem. Ou melhor, a escrita desses contos se caracteriza por um movimento duplo: o da somatória de lances romanescos, construindo o sentido linear (ou funcional) do texto, e o da repetição, marcado pela figura, que enuncia o retorno do já-dito, uma vez que é indicadora da velha tópica que a ironia da escrita repete, indeterminando o sentido unívoco da narrativa pelo jogo do pastiche. Daí o efeito de anacoluto provocado pela comparação, que anula a causalidade da verossimilhança, evidenciando o artifício da escrita. Seguem-se outros trechos do conto flaubertiano:

La nuit allait venir; et derrière le bois, dans les intervalles des branches, le ciel était rouge comme une nappe de sang. [...]

Il y avait dans son feuillage un choucas monstrueux, qui regardait Julien; et çà et là, parurent entre les branches quantité de larges étincelles, comme si le firmament eût fait pleuvoir dans la fôret toutes ses étoiles. C'étaient des yeux d'animaux, des chats sauvages, des écureuils, des hiboux, des perroquets, des singes ${ }^{7}$. (FLAUBERT, [1877] 1973, p. 99 e 114, respectivamente)

\footnotetext{
7 "A noite estava para chegar; e por trás do bosque, nos intervalos dos ramos, o céu parecia vermelho como um lençol de sangue. [...] Havia em meio à folhagem uma gralha monstruosa, que fitava Julião; cá e lá, surgiram entre os ramos inúmeras centelhas alongadas, como se o firmamento fizesse chover sobre a floresta todas as suas estrelas. Eram os olhos de animais, gatos selvagens, esquilos, corujas, papagaios, macacos.” (FLAUBERT, [1877] 2004, p. 67 e 77, respectivamente).
} 
Percebe-se que nos dois exemplos a comparação corta a sequência linear dos episódios, desmascarando o procedimento da escrita: o lugar-comum de suas imagens, construídas pela relação de similitude entre sangue e cor vermelha (remetendo também intradiegeticamente à caça de Julien), estrelas e olhos, longe de apenas oferecer ao leitor uma construção imagética ordinária, assinala o pastiche das aventuras. Pois a imagem, pontuando os lances romanescos tornados kitsch, sobrepõe outra voz à voz narrativa que conta as aventuras de Julien: a do anonimato do clichê, que faz o leitor se perguntar quem é o sujeito da enunciação. Pergunta provavelmente sem resposta, visto que o artifício do narrador em primeira pessoa, revelado no final do conto, não deixa de ser apenas artifício: "Et voilà l'histoire de saint Julien l'Hospitalier, telle à peu près qu'on la trouve, sur un vitrail d'église, dans mon pays" (FLAUBERT, [1877] 1973, p. 129). Assumindo valor semântico da indefinição gramatical do pronome on, aliás explícito, o pronome em primeira pessoa fica despojado da singularidade que o caracterizaria para se investir da responsabilidade pela voz. Também não funciona como artifício retórico mimético da legenda medieval: toda a ironia da fórmula "à peu près" não deixa de evidenciar sua falha.

Em outras palavras, o efeito de anacoluto da comparação vem da entrada em cena da bêtise, que sinaliza o pastiche das tópicas kitsch, deslocando, deste modo, a representação semântica das aventuras de Julien. Entenda-se aqui a estreita relação entre a estupidez e o anonimato da voz que faz a comparação: não que a imagem clichê seja necessariamente "estúpida", mas torna-se bête pela ironia da escrita que enfatiza a tópica piegas. Ou seja, o uso do clichê ressalta a besteira das ideias feitas (besteira de se terideias feitas), do repertório kitsch que a narrativa põe em jogo. O efeito de anacoluto da comparação faz do conto, portanto, uma maquinaria narrativa, produção de uma voz que só com muito fingimento assume o papel de um eu. Como o narrador tagarela de Machado, o eu fingido do conto flaubertiano fala, e fala sem informar ao leitor donde sai sua voz, sabotando, assim, a veiculação de significações verossímeis. E como efeito do efeito de anacoluto da comparação, eis a indeterminação da narrativa pelo deslocamento constante da representação mimética das peripécias de Julien. Deslocamento que, é bom repetir, se não permite uma leitura realista e positivista do(s) conto(s), também não permite uma leitura de total adequação ao gênero legendário (ou fantástico, no caso de "O imortal"), visto que a ironia do pastiche desfaz qualquer possibilidade de representação séria, seja ela "realista" ou "fantástica". Volta-se agora à narrativa machadiana: "Imaginem que meu pai, em 1695, entrou na conquista da famosa república dos Palmares. Bateu-se como um bravo, e perdeu um amigo, um amigo íntimo, crivado de balas, pelado..." (ASSIS, [1882] 2006, v. 2, p. 895).

Ou ainda: "Casou com D. Helena, bela como o sol, dizia ele”. E logo adiante, a mesma comparação, mas para outra personagem: "Saiu dali para Madri, onde esteve de amores com duas fidalgas, uma delas viúva e bonita como o sol, a outra casada, menos bela, porém amorosa e terna como uma pomba-rola" (ASSIS, [1882] 2006, v. 2, p. 896 e 897, respectivamente).

No primeiro desses três exemplos, a coloquialidade do termo "pelado", antes de opor-se à seriedade de bater-se "como um bravo", acentua a ironia da representação da valentia do herói, desdizendo da gravidade do código de honra já desacreditado, o que reitera seu caráter cômico. Gesto irônico que desestabiliza a credibilidade da narrativa, ou melhor, sua plausibilidade, mesmo tendo-se em vista seu aspecto fantástico. Nos exemplos seguintes, a repetição da mesma comparação para duas personagens diferentes, além de irônica quanto à devoção e à promessa de amor eterno a D. Helena, acentua também a ironia do próprio pastiche, pois sinaliza ao leitor a repetição da tópica amorosa. Ironia que, maliciosamente, se enfatiza com a imagem piegas "amorosa e terna como uma pomba-rola”. Como em Flaubert, a repetição da figura (considerando-se aqui não apenas a repetição dos últimos trechos citados, mas sobretudo como uma repetição estrutural), dificultando a funcionalidade da representação da trama, indetermina a narrativa enquanto comunicação de conteúdos unívocos. Indeterminação, a propósito, explícita no final do conto: como a ironia da fórmula flaubertiana "à peu

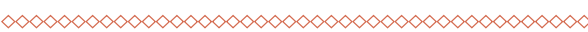

8 "Eis aqui a história de São Julião Hospitaleiro, mais ou menos como se encontra num vitral de igreja da minha terra." (FLAUBERT, [1877] 2004, p. 88). 
près", o narrador pluraliza virtuais significações da história de Rui de Leão, de acordo com diferentes regimentos plausíveis de verossimilhança:

O coronel e o tabelião ficaram algum tempo calados, sem saber que pensassem da famosa história; mas a seriedade do médico era tão profunda, que não havia duvidar. Creram no caso, e creram também definitivamente na homeopatia. Narrada a história a outras pessoas, não faltou quem supusesse que o médico era louco; outros atribuíram-lhe o intuito de tirar ao coronel e ao tabelião o desgosto manifestado por ambos de não poderem viver eternamente, mostrando-lhes que a morte é, enfim, um benefício. Mas a suspeita de que ele apenas quis propagar a homeopatia entrou em alguns cérebros, e não era inverossímil. (ASSIS, [1882] 2006, v. 2, p. 900)

O narrador finaliza o conto com tais palavras e tal ironia que, desde a primeira leitura, faz lembrar o final de "La légende de Saint Julien l'Hospitalier", remetendo também a outro conto machadiano, "Ruy de Leão", publicado dez anos antes, conforme já está dito. Ainda como a fórmula "à peu près" da narrativa de Flaubert, a situação enunciativa encenada no final do conto coloca em suspenso toda a leitura que o leitor acaba de fazer: "Dou este problema aos estudiosos. Tal é o caso extraordinário, que há anos, com outro nome, e por outras palavras, contei a este bom povo, que provavelmente já os esqueceu a ambos". (ASSIS, [1882] 2006, v. 2, p. 900)

Dispositivo da maquinaria narrativa que, ativando o clichê, desvela o procedimento da escrita, a figura é a ironia efetivada por meio da comparação, fazendo com que a representação da mímesis do démodé deixe de corresponder a uma construção ficcional verossímil para pôr em questão e corroer a própria representabilidade. Evidenciando a inadequação à representação séria dos valores em jogo nas narrativas (a saber, a honra, a valentia, o amor eterno etc.), a figura impossibilita a causalidade da verossimilhança, pois, ao enfatizar com seu demonstrativo imagético as semelhanças que a efetivariam, sinaliza a artificialidade da tópica narrada. Isto é, as semelhanças já estão desgastadas e as opiniões não sustentam mais como verossímeis o idealismo que motiva as intrigas romanescas de Julien e de Rui de Leão, a menos que participem do "malfazejo de uma hipocrisia universal na maneira de viver, perdida em imensos cerrados de sentimentos e de convenções", conforme as palavras de Hermann Broch (2001, p. 34) sobre o kitsch. "É supérfluo ressaltar que a burguesia jogou hipocritamente a comédia do triunfo completo de sua atitude. Durante todo o século XIX, ela aparentou ter trazido para a vida a grande arte e exterminado, além disso, a libertinagem" (BROCH, 2001, p. 34-35; tradução minha).

Mantendo a "estrita necessidade" de se conservar "como classe distinta diante da classe feudal que cedia o terreno", a burguesia afirma "os ideais ascéticos do puritanismo calvinista" nos países protestantes, ou, nos católicos, o "princípio diretor universal" assentado na "virtude" (BROCH, 2001, p. 17). Mas ao longo do século XIX, a bem conhecida divisa de hoje "time is money" já modelava os corpos e a vida e todo blablablá de amor eterno, honra e valentia ia por água abaixo pelo ralo do capital. Ou ficava (e ainda fica) como água estagnada, como bêtise que universaliza as particularidades na hipocrisia kitsch do idealismo. Apontando semelhanças discursivas já arruinadas (ou "convenções", para falar nos termos de Broch, desmascaradas como ideológicas), a ironia efetivada pela figura fica aqui denominada por "comparação-kitsch".

Ressalta-se que não é kitsch por seu excesso, mas pela semelhança universalizante que pressupõe. Ou seja, semelhança refletora de uma anterioridade ontológica, verdade originária ou fundamento substancial das palavras, que faria funcionar a representação semântica da narrativa, pois a fixaria em unidades de sentido ("amor", "valentia", "morte" / "imortalidade", etc.) reconhecíveis pelo leitor. Todavia, conforme está dito, a ironia na comparação-kitsch aponta as semelhanças desgastadas, sublinhando a inverossimilhança da valentia de Julien e das aventuras amorosas de Rui de Leão, mesmo pela lógica do verossímil dos gêneros legendário e fantástico. Enfatiza-se, mais uma vez, que ambas as 
narrativas deslocam a verossimilhança dos gêneros textuais que elas evocam, seja a "legenda" que se dissolve no "conto", seja o "fantástico" que baralha critérios realistas / positivistas, visto que o imortal é mortal. O que é kitsch aqui, portanto, não é o detalhe desnecessário ou o ornamento excessivo, como quer Abraham Moles ${ }^{9}$ (1971), mas a universalização como regra, ideias feitas que se repetem na tirania do babitus ${ }^{10}$. Ou as juras de amor eterno à mulher "bela como o sol" e os olhos que refletem o brilho das estrelas.

Evidenciando a historicidade dos discursos e das verossimilhanças, como afirma Hansen (2006), a comparação-kitsch aponta também a do leitor, pois é o texto que o lê, e não o contrário. O kitsch só é kitsch com uma certa raiva da besteira e as escritas de Machado e de Flaubert só são críticas se o leitor se deixa ser falado por elas, pois, o kitsch é o efeito de um ponto cego da figura, da comparação que se faz "figural", para pensar com Deleuze ${ }^{11}$ (1984), silenciando, assim, sua representabilidade semântica. Com isso, afirma-se que não se trata de revelar a "verdade" do(s) texto(s) e a "intenção" unívoca dos autores com a escrita de suas narrativas. Fala-se aqui em "Machado" ou "Flaubert" como um lugar de relação, congruência entre escrita e leitura.

Efetivamente, a relação que se faz pelo registro irônico - e sublinha-se aqui que a ironia é justamente o que produz a inadequação da escrita a categorias de sentido que possam determinar a "intencionalidade" unívoca de seus autores - pressupõe ainda a "intenção" da ironia. Entretanto, ressalta-se que não se trata de "expressividade", mas de uma política da escrita que sugere outros modos de ler e de escrever, que não aqueles fixados pela repetição mimética. Por isso, não se fala aqui sobre os textos e seus autores, mas fala-se a partir deles. Porque falar sobre ainda é falar de fora, é considerar o discurso literário um objeto delimitado e determinado por fatores histórico-sociais ou estritamente narratológicos. Falando sobre, a crítica machadiana preenche as lacunas de sentido da escrita com unidades de significação, pressupondo que o texto seja reflexo de conteúdos empíricos, e determina, desse modo, sua indeterminação com interpretações alegóricas, instrumentalizando-o para que se fale sobre o Brasil. Porque pensa-se no e com o projeto romântico literário e não se considera que as semelhanças estão desfeitas ${ }^{12}$.

Repete-se que o procedimento irônico da escrita de Machado se faz pela indeterminação da narrativa como unidade de sentido, impossibilitando a reprodução harmônica dos sistemas de representação do leitor. Assim como Flaubert no século das correspondências baudelairianas ou do que, logo mais, será o signo da verdade de Proust, as semelhanças se mostram desgastadas e as correspondências interrompidas na besteira das ideias feitas. Propondo aqui "Machado com Flaubert", o que se sugere é prescindir da necessária correspondência entre texto e conteúdos da realidade nacional, pois $\infty<\infty<\infty<\infty<\infty<\infty<\infty<\infty<\infty<\infty<\infty<\infty<\infty<\infty<\infty<\infty<\infty<\infty<\infty$

${ }^{9}$ Perspectivada pela estética do funcionalismo do movimento Bauhaus, Moles associa o kitsch anacronicamente ao estilo "Barroco" ou "Rococó", afirmando que se trata de "um fenômeno social universal, permanente, de grande envergadura" (MOLES, 1971, p. 11), relacionado ao acúmulo e à sinestesia. Essa definição, entretanto, pode ser também kitsch, dado que pressupõe a universalidade de uma visão parcial e particular. Neste sentido, não se encontrará aqui uma nova definição do termo, pois, o que se está em jogo é a impossibilidade da tranquilidade ontológica do conceito.

${ }^{10}$ Emprega-se este termo em seu sentido antropológico mais geral. Segundo o Dicionário Eletrônico Houaiss da Língua Portuguesa (versão 1.0.5, agosto de 2002), "habitus" é o "modo de ser de um indivíduo ligado a um grupo social, que se relaciona especialmente com a aparência física (roupa, atitude etc.)". "Aparência física" que, enfatiza-se aqui, está intrinsecamente relacionada às práticas de legibilidade normativa do corpo. Sobre o "sabá da besteira e da maldade" em que o habitus opera tiranicamente, ver Gilles Deleuze (2006).

${ }^{11}$ Seguindo a proposta de J.-F. Lyotard, o "figural" da pintura de Francis Bacon opõe-se ao "figurativo", à representação que "implica, de fato, relacionar uma imagem a um objeto, buscando ilustrá-lo" (DELEUZE, 1984, p. 10 ; grifos e tradução meus). Além do texto de Deleuze, pensa-se também na figura como "silêncio" semântico da narrativa, conforme a leitura de Gérard Genette (1966), em "Silences de Flaubert".

${ }^{12}$ Entendam-se aqui não apenas a crítica contemporânea à produção machadiana, mas também a que lhe é posterior. Convém, no entanto, fazer a ressalva dos trabalhos de Abel B. Baptista (2003), que, ao analisar o artifício dos autores fictícios da escrita de Machado (Brás Cubas e Dom Casmurro), faz uma nova leitura dos textos, ressaltando a ficcionalização da autoria e a consequente não-resposta pelo livro, que indeterminam a univocidade de significações das narrativas e da "intenção" de "Machado de Assis" ao escrevê-las. 
pressupõe-se que a escrita literária não é reflexo (crítico ou não) do mundo empírico, relação mecânica entre o que se chama "literatura" e seu tempo histórico. Nem tampouco é a forma desistoricizada, como se a mesma não fosse intrinsecamente ligada a outros discursos, modeladores da vida e dos corpos. O que aqui se propõe, em uma palavra, é a política da escrita que, pelo jogo de seus artifícios, evidencia a historicidade do simbólico, desnaturalizando os modos de ler. Porque o ato político da escrita se mostra pelo silenciamento da representação semântica das narrativas: deslocando sua função meramente representativa, as escritas de Machado e de Flaubert salientam a manipulação da linguagem e fazem Quincas Borba encontrar a dupla Bouvard e Pécuchet no limite tênue entre o pensamento mais elevado e a besteira.

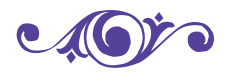

\section{Referéncias OBiblicgräficas}

ARISTOTE. Rhétorique (Livre III). Paris: Gallimard, 1991. (Tel).

ASSIS, M. de. Obra completa. $12^{a}$ ed. Rio de Janeiro: Editora José Aguilar, 2006.

BAPTISTA, A. B. A formaşão do nome: duas interpretações sobre Machado de Assis. Campinas: Editora da Unicamp, 2003.

BROCH, H. Quelques remarques à propos du kitsch. (Traduit de l'allemand par Albert Kohn). Paris : Éditions Allia, 2001.

DELEUZE, G. Logique de la sensation. v. 1. 2a ed. Paris: Éditions de la différence, 1984. . Diferença e repetição. $2^{\mathrm{a}}$ ed. Rio de Janeiro: Graal, 2006.

FLAUBERT, G. Trois contes [1877]. Paris : Gallimard, 1973. (Folio Classique). 2004. . Três contos [1877]. (Tradução de Milton Hatoum e Samuel Titan Jr.). São Paulo, Cosac Naify,

HANSEN, J. A. “'O imortal' e a verossimilhança”. Teresa: revista de Literatura Brasileira, São Paulo, Editora 34 / Impressa Oficial, no 6-7, 2006, p. 56-78.

GENETTE, G. “Silences de Flaubert”. Figures I. Paris: Seuil, 1966, p. 223-243. (Points).

GUIMARÃES, H. S. Os leitores de Machado de Assis. São Paulo: Nankin Editorial / Edusp, 2004.

KRISTEVA, J. "A produtividade chamada texto". Introducão à semanálise [Recherches pour une sémanalyse, 1969]. (Tradução de Lúcia Helena França Ferraz). São Paulo: Perspectiva, 1974.

MASSA, J.-M. A juventude de Machado de Assis 1839-1870. Rio de Janeiro: Civilização Brasileira / Conselho Nacional de Cultura, 1971.

MOLES, A. O kitsch: a arte da felicidade [1971]. (Tradução de Sergio Miceli). $2^{a}$ ed. São Paulo: Editora Perspectiva, 1975. 